\title{
Long-Term Antecedents and Outcomes of Perceived Control
}

\author{
Frank J. Infurna ${ }^{1}$, Denis Gerstorf ${ }^{1,2,3}$, Nilam Ram ${ }^{1,2,3}$, Jürgen Schupp ${ }^{3,4}$, and Gert G. \\ Wagner $2,3,5$
}

Frank J. Infurna: infurna@psu.edu; Denis Gerstorf: gerstorf@psu.edu; Nilam Ram: nilam.ram@psu.edu; Jürgen Schupp: jschupp@diw.de; Gert G. Wagner: gwagner@mpib-berlin.mpg.de

${ }^{1}$ Pennsylvania State University, University Park, USA

2Max Planck Institute for Human Development, Berlin, Germany

${ }^{3}$ DIW Berlin (German Institute for Economic Research), Germany

${ }^{4}$ Free University, Berlin, Germany

${ }^{5}$ Berlin University of Technology, Germany

\section{Abstract}

Perceived control plays an important role in shaping development throughout adulthood and old age. Using data from the adult lifespan sample of the national German Socio-Economic Panel (SOEP; $N>10,000$, covering 25 years of measurement), we explored long-term antecedents, correlates, and outcomes of perceived control and examined if associations differ with age. Targeting correlates and antecedents of control, findings indicated that higher concurrent levels of social participation, life satisfaction, and self-rated health as well as more positive changes in social participation over the preceding 11 years were each predictive of between-person differences in perceived control. Targeting health outcomes of control, survival analyses revealed that perceived control predicted 14-year hazard rates for disability ( $n=996$ became disabled) and mortality ( $n=1,382$ died). The effect for mortality, but not for disability, was independent of socio-demographic and psychosocial factors. Overall, we found very limited support for agedifferential associations. Our results provide further impetus to thoroughly examine processes involved in antecedent-consequent relations among perceived control, facets of social life, wellbeing, and health.

\section{Keywords}

Control; Lifespan Development; Disability; Mortality; Psychosocial

\footnotetext{
Address correspondence regarding this manuscript to: Frank J. Infurna, Department of Human Development and Family Studies, The Pennsylvania State University, 118 Henderson Building, University Park, PA 16802, USA, infurna@psu.edu.

Frank J. Infurna, Department of Human Development and Family Studies at the Pennsylvania State University, PA, USA; Denis Gerstorf and Nilam Ram, Department of Human Development and Family Studies at the Pennsylvania State University and Max Planck Institute for Human Development, Berlin, Germany and German Socio-Economic Panel Study at the DIW Berlin, Germany; Jürgen Schupp, German Socio-Economic Panel Study at the DIW Berlin, Germany and Free University of Berlin, Germany; Gert G. Wagner, Max Planck Institute for Human Development, Berlin, Germany and German Socio-Economic Panel Study at the DIW Berlin, Germany and Berlin University of Technology (TUB), Germany.

Publisher's Disclaimer: The following manuscript is the final accepted manuscript. It has not been subjected to the final copyediting, fact-checking, and proofreading required for formal publication. It is not the definitive, publisher-authenticated version. The American Psychological Association and its Council of Editors disclaim any responsibility or liabilities for errors or omissions of this manuscript version, any version derived from this manuscript by NIH, or other third parties. The published version is available at www.apa.org/pubs/journals/pag

The content is solely the responsibility of the authors and does not necessarily represent the official views of the funding agencies. Special thanks to Jennifer Morack for helpful comments on previous versions of this work.
} 
Individuals' perceived control plays an integral role for adult development and successful aging (Baltes \& Baltes, 1986; Bandura, 1997; Brandtstädter, \& Greve, 1994; Heckhausen \& Schulz, 1995; Krause, 2007; Lachman, 2006; Rowe \& Kahn, 1987; Uchino, 2006). Conceptual frameworks and empirical reports both suggest that perceived control is related to central indicators of engagement, well-being, and health (Femia, Zarit, \& Johansson, 1997; Kunzmann, Little, \& Smith, 2002; Penninx et al., 1997; Rodin, 1986; Skaff, 2007). However, because the evidence is often based on cross-sectional or short-term longitudinal data, little is known about the underlying long-term developmental dynamics and whether these associations differ across adulthood and old age. In the current study, we use data from the adult lifespan sample of the German Socio-Economic Panel (SOEP) to explore longterm antecedents, correlates, and outcomes of perceived control. First, targeting correlates and long-term antecedents of control, we explore the role of socio-demographic variables as well as level and preceding time-related changes in social participation and life satisfaction for perceived control. Second, targeting health outcomes, we examine whether perceived control is predictive of subsequent 14-year hazard rates for disability and mortality. Of central importance to us was if and how these antecedent-consequent associations differ with chronological age.

Perceptions of control refer to the belief that changes in the environment are contingent upon one's own actions, efforts, and choices (Fung, Abeles, \& Carstensen, 1999; Krause, 2003; Levenson, 1981; Skinner, 1996). In our study, we draw from Lachman's (2006) integrative conceptual model which outlines that perceived control is both a consequence of resources in the social, well-being, and health domains and an antecedent condition that in turn fosters health and other key behaviors contributing to successful aging. For example, interactions with network members may inspire and enlarge one's feelings of control to perform health-promoting behaviors, leading to more positive health profiles; in turn, individuals perceiving themselves in control may be more likely to draw from and utilize social resources in times of strain (see also Antonucci, 2001; Skaff, 2007; Uchino, 2006). A second component of Lachman's model is that background factors (i.e., age, education, and gender) moderate antecedent-consequent associations with perceived control. In this study, our objective is to examine whether age moderates antecedent-consequent associations of perceived control. For example, health-control associations may be particularly strong in old age when frequent or severe health decrements can prototypically be expected (Rodin, 1986).

\section{Correlates and Antecedents of Perceived Control}

Perceived control is often assumed to be shaped by resources in central areas of functioning, including the social, well-being, and physical health domains. To begin with, several theoretical accounts propose that supportive social experiences and exchanges contribute to individuals' perceptions of control (Antonucci \& Jackson, 1987; Bandura, 1977; Deci \& Ryan, 1995). For example, self-efficacy theory details that key social interactions such as verbal persuasion and modeling of behavior represent two major sources of control and efficacy beliefs (Bandura, 1977). Therefore, through interactions and modeling of network members, beliefs of control and efficacy become internalized and eventually increase the frequency with which individuals engage in effective behaviors. In line with those notions, evidence suggests that social participation and support from network members is related to higher levels of perceived control (Krause, 1987; Lang, Featherman, \& Nesselroade, 1997; Pearlin et al., 1981). Similarly, associations between perceived control and facets of wellbeing have been documented. For example, McAvay, Seeman, and Rodin (1996) found that participants with depressive symptoms were at risk for subsequent three-year declines in self-efficacy. Furthermore, several studies have shown that negative affect discourages efforts for enacting control (Schulz \& Heckhausen, 1998). Finally, health limitations may 
undermine feelings of control (for discussion, see Rodin, 1986). For example, longitudinal reports indicate that aspects of poor health (e.g., chronic illnesses, impaired physical functioning, and low self-rated health) are related to a lowered sense of control (Cairney et al., 2007; Wurm et al., 2007).

Perceived control is also known to differ across socio-demographic strata, including age, socioeconomic status, and gender. Several cross-sectional studies document, for example, that older adults are more likely to report lower feelings of control as compared with middleaged adults (Lachman \& Weaver, 1998; Mirowsky, 1995). In older ages, repeated experiences of less controllable events such as social losses or health limitations may drag one's sense of control down (Rodin, 1986). Socioeconomic status variables such as education, income, and work history status also relate to level differences in facets of control. For example, more years of schooling strengthens perceptions of control by enhancing one's problem-solving abilities and having better access to control-boosting resources (e.g., higher income, better work conditions; Lachman \& Weaver, 1998; Ross \& Mirowsky, 2002). Lastly, research shows that women report lower perceived control, primarily because of lifetime disadvantages in education, personal employment history, income, and physical functioning especially among current cohorts of older women (Feingold, 1994; Lachman \& Firth, 2004). The empirical evidence on gender differences in control, however, is less than conclusive (see Ross \& Mirowsky, 2002).

We will also examine whether antecedents of perceived control differ across adulthood and old age. It is an open question, whether such associations are stronger or weaker in old age. For example, relative to midlife, health problems are more common and often more serious in old age (Aldwin et al., 2006). Health decrements in available resources of strength and vitality can undermine and exert limitations on older adults' control efforts, resulting in perceived control being particularly vulnerable to the detrimental effects of compromised health (Rodin, 1986). Consistent with this reasoning, Pearlin and colleagues (2007) reported that recent stressful, negative life events had stronger effects on mastery beliefs in the oldold than in the young-old. A contrasting scenario is that older adults (consciously or not) turn away from using the health domain as a source of control. As a consequence, in older ages, more controllable and attainable sources such as social support and well-being become increasingly important in contributing to control perceptions (Heckhausen et al., 2010).

\section{Health Outcomes of Perceived Control}

Perceived control also acts as an antecedent condition fostering health and other key outcomes of successful aging. Several theoretical notions argue that personal resources (among others, perceived control) influence the onset and progression of disability (e.g., Disablement Process; Verbrugge \& Jette, 1994). For example, people who perceive themselves to be in control are better able (and have greater self-efficacy) to utilize their resources so that functional limitations do not necessarily turn into full-blown disability. Conceptual considerations that perceived control represents a highly adaptive quality map onto empirical results from numerous studies of midlife and older adults reporting that aspects of perceived control relate to key health measures (Baltes \& Baltes, 1986; Kunzmann et al., 2002). For example, findings from the MacArthur Studies of Successful Aging indicated that self-efficacy serves as a protective factor against functional decline over a 2.5 year period (Seeman et al., 1999). Over a similar time frame, mastery buffered the onset of disability and progression of functional decline in samples of the oldest old (Fauth, Zarit, Malmberg, \& Johansson, 2007; Femia et al., 1997). In longitudinal studies with follow-ups spanning 10 and more years, feelings of control and self-confidence were also protective of health declines in both midlife and old age (Caplan \& Schooler, 2003; Gerstorf, Röcke, \& Lachman, 2011). 
Facets of control have also been shown to be predictive of longevity. For example, several studies have shown that lower feelings of control and mastery predict all-cause mortality over follow-ups of 2.5 years (Penninx et al., 1997), 4.8 years (Surtees, Wainwright, Luben, Khaw, \& Day, 2006), and 11 years (Surtees et al., 2010). In a similar vein, Krause and Shaw (2000) reported that greater feelings of control in one's most salient role in life (but not global feelings of control) were predictive of all-cause 6-year survival. When targeting specific causes of death, the evidence suggests that perceived control is particularly associated with cardiovascular mortality, but not with cancer mortality (Surtees et al., 2006, 2010). Following several streams of theoretical and empirical work, perceived control may be related to all-cause mortality through various mechanisms, including health-promoting behaviors, emotion regulation, social integration, and stress buffering effects. For example, individuals reporting lower control beliefs are less inclined to adopt and continue with health maintenance behaviors such as exercise and preventive care (Rodin, 1986; Seeman, Unger, McAvay, \& Mendes de Leon, 1999). As a consequence, lower perceived control may alter one's behavioral and physiological functioning, probably leading to increased vulnerability to diseases and subsequent mortality.

We acknowledge that our survival analyses do not control for key objective health indicators included in other studies such as grip strength, gait variability, or allostatic load (Crimmins et al., 2005; Seeman et al., 2002; Weir, 2008). Such detailed health assessments in largescale epidemiological studies are often costly, if not cost-prohibitive and thus very difficult to implement. Admittedly, our report thus suffers from assessment disadvantages, but in our view those are outweighed by sampling advantages (e.g., large nationally representative samples, covering the entire adult age range, long duration of the study, wide range of available data, etc.). We also note that including self-rated health as an additional covariate into our survival analyses should provide for a conservative test of whether or not perceived control reveals unique predictive effects. More specifically, extensive meta-analytic work has suggested that self-rated health typically reveals the more robust and stronger predictive effects for mortality than many objective health indicators such as medically diagnosed illnesses (Idler \& Benyamini, 1997).

We will also examine whether the health implications of perceived control differ across adulthood and old age. We argue that the effects of perceived control and associated (healthrelated) behaviors need time to evolve and accumulate. As a consequence then, the beneficial effects of greater perceived control or the detrimental effects of low perceived control should be more pronounced and visible in later phases of life relative to earlier phases (see Elder \& Johnson, 2003; Fauth et al., 2007; Krause \& Shaw, 2000). Consistent with this conceptual reasoning, Infurna, Gerstorf, and Zarit (in press) found in the adult lifespan sample (ages 25 -96) of the Americans' Changing Lives study that perceived control was predictive of subsequent health changes in old age, but not in midlife. In young adulthood and midlife, perceived control may relate to health behaviors and alterations in physiological function, whose effects take longer to accumulate, may be subclinical, and lead to increased vulnerability to disability and mortality. Conversely, in old age, such effects have often accumulated over a long period of time. As a consequence, reduced control in old age should have more immediate and proximal consequences for worsening of health.

\section{The Present Study}

We aim to extend and qualify earlier insights into possible antecedents, correlates, and consequences of perceived control across adulthood and old age by using data from the adult lifespan sample of the national SOEP. Previous evidence regarding antecedents and outcomes of perceived control has in most cases been based on cross-sectional or short-term 
longitudinal data, and we aim to utilize long-term longitudinal data to examine the underlying developmental dynamics and whether these associations differ across adulthood and old age. Figure 1 graphically depicts an overview of the relevant SOEP data as utilized in our study. In a first step, we target correlates and long-term antecedents of perceived control to examine if between-person differences in socio-demographic variables as well as level and preceding time-related changes in social participation and life satisfaction are predictive of between-person differences in perceived control. Perceived control was assessed in 1994, and we will examine how within-person changes in the social and wellbeing domains that occurred over the preceding 11 years relate to perceived control (i.e., from 1984 to 1994). Levels of functioning represent snapshot assessments at a given point in time, whereas time-related changes may be an indicator of changes in individuals' resources in specific domains of functioning and thus provide an added, distinctive perspective to the prediction of between-person differences in perceived control. For example, time-related change may be especially critical in older ages when expected decrements in domains such as one's social life may profoundly affect perceived control.

In a second step, we target outcomes of perceived control and apply survival analyses to examine if and how between-person differences in perceived control are predictive of between-person differences in the hazard rates for disability and mortality over the subsequent observation period of 14 years. We aim to add to earlier studies examining control-health associations and help reconcile divergent findings. Specifically, the national representativeness of the SOEP allows us to generalize to the larger population, a lengthy follow-up period to extend previous findings, and the inclusion of a broad range of sociodemographic and psychosocial factors as covariates to examine if control-health associations are independent of known correlates. Lastly, we are particularly interested in examining whether the role of these variables as long-term antecedents, correlates, and outcomes of perceived control differ across adulthood and old age.

\section{Method}

We examined our research questions using data from the SOEP (Headey et al., in press). Comprehensive information about the design, participants, variables, and assessment procedures in the larger study is reported in Wagner, Frick, \& Schupp (2007). A brief overview of details relevant to the present analysis is given below.

\section{Participants and Procedure}

The SOEP is a nationally representative annual panel study of private households initiated in 1984 that covers $\sim 40,000$ residents, including immigrants and resident foreigners, of former West and East Germany. Potential participants were randomly selected from a set of randomly selected geographic locations in Germany. Within each household, all family members older than 16 years of age were eligible for participation. Relatively high initial response rates (between 60\% and 70\%) and low longitudinal attrition (about 15\% for the second wave and less than 5\% yearly attrition across various subsamples) provide for an overall sample that is representative of the population living in private households (Kroh \& Spiess, 2006; Kroh, Pischner, Spiess, \& Wagner, 2008) and long-term care homes in Germany (Klein, 1996). Data were primarily collected via face-to-face interviews, with the exception that about $10 \%$ of individuals who had already participated several times provided data via self-administered questionnaires.

For the present study, we make use of data on perceived control gathered in 1994. With an interest in studying long-term antecedents, correlates, and outcomes of perceived control, we made use of the SOEPs annual data collection waves and continuous tracking of health status between 1984 and 2008 (for overview, see Figure 1). Included in our antecedent 
analyses were a total of 10,894 participants (age 16 to 97 years) who (a) completed the perceived control questionnaire in 1994 and (b) provided data for the correlates (e.g., sociodemographic variables and social, well-being, and health domains) during the years 1984 and 1994. Descriptive statistics for this sample are shown in the top portion of Table 1. To quantify selectivity effects, we compared this subsample with the larger SOEP parent sample of $\sim 40,000$ participants. Analyses revealed that participants included in our antecedent analyses were younger at their first measurement occasion $(M=37.68, S D=$ 16.13 vs. $M=40.29, S D=18.67 ; F[1,48,119]=175.30, p<.05)$, attained fewer years of education $(M=11.18, S D=2.40$ vs. $M=11.40, S D=2.73 ; F[1,43,889]=54.91, p<.05)$, and included more women $\left(52 \%\right.$ vs. $\left.51 \% ; \chi^{2}[1,48,606]=11.65, p<.05\right)$.

Included in our outcome analyses were a total of 10,824 participants (age 16 to 97 years) who provided data on all measures of interest (i.e., perceived control, the covariates, and the health outcomes of disability and mortality). Descriptive statistics for this sample are shown in the bottom portion of Table 1. To quantify selectivity effects, we compared this subsample with the larger SOEP parent sample of $~ 40,000$ participants. Analyses revealed that participants included in our outcome analyses were younger at their first measurement occasion $(M=37.65, S D=16.13$ vs. $M=40.27, S D=18.67 ; F[1,48,119]=174.04, p<$. $05)$, attained fewer years of education $(M=11.19, S D=2.41$ vs. $M=11.40, S D=2.73 ; F[1$, $43,644]=50.19, p<.05)$, and included more women $\left(53 \%\right.$ vs. $51 \% ; \chi^{2}[1,48,121]=12.85$, $p<.05)$. Although significant, the relatively small differences in substantive terms suggest that the study samples are comparable to the study population from which they were drawn.

\section{Measures}

Perceived control was measured using an 8-item index assessing the degree to which individuals feel their life is under their control. The Appendix contains the perceived control items as administered in German and their corresponding English translation. The scale is highly similar in structure to other instruments being used to assess perceived control (see Lachman \& Weaver, 1998; Pearlin \& Schooler, 1978). Items were averaged, with positively valenced items reverse coded to create an index with higher scores indicating greater perceived control (Cronbach's $\alpha=.71$ ).

Disability-Two scores were derived from the longitudinal indicators of disability status to indicate the timing of disability onset and disability status in 1994. Disability was assessed at each assessment with a single item asking participants whether they had been "officially certified as having a reduced capacity to work or being severely handicapped" (for details, see Lucas, 2007). Thus, disability indicators were based on self-reports, but referred to official certifications. Time of disability onset was calculated as the year at which participants first reported being disabled. Of the 10,824 participants included in our outcome analyses for disability, 728 (or 6.73\%) were already disabled in 1994, and another 996 participants (or 9.20\%) experienced disability over the 14-year observation period. On average, participants with incident disability during the follow-up period were 53.22 years of age in $1994(S D=14.61$, range $17-93)$ and became disabled 7.29 years later $(S D=3.98$, range $1-14$ ). To create mutually exclusive and collectively exhaustive categories for the survival analyses, we treated all participants who reported becoming disabled at one occasion as remaining disabled at all subsequent occasions. Follow-up analyses excluding those 339 participants who fluctuated between disability states revealed substantively similar findings to those reported. Disability status indicated whether or not an individual was disabled in 1994 and was included in our correlates and antecedents analyses.

Mortality-Timing of death for deceased participants was obtained either by interviewers at yearly assessments (i.e., from household members, or in the case of one-person households, 
neighbors) or from city registries and other authorities (for details, see Gerstorf, Ram, et al., 2008). Of the 10,824 participants included in our mortality analyses, 1,382 participants (or $12.78 \%$ ) had died during the 14 years of follow-up. On average, deceased participants were 66.92 years of age in $1994(S D=13.72$, range $17-97)$ and died 7.54 years later $(S D=4.15$, range $1-14)$. At the time of death, 29 participants $(2 \%)$ were in young adulthood (aged $23-$ 39 ), 410 participants (30\%) were in midlife (aged $40-69)$, and 943 participants $(68 \%)$ were in old age (aged 70 and older). Information on specific causes of death is not yet available in SOEP. Thus, our analysis is limited to testing whether perceived control is associated with all-cause mortality. We nevertheless acknowledge that causes of death likely differed with age (e.g., the most common causes of death among young adults include accidents and suicide, whereas older adults tend to die as a result of cardiovascular diseases and cancer; Centers For Disease Control and Prevention, 2005).

Self-rated health was assessed using a single item, "Wie würden Sie Ihren gegenwärtigen Gesundheitszustand beschreiben?" ("How would you rate your health at the present time?"). The item was answered using a 5-point Likert scale $(1=$ bad to $5=$ very good $)$ and has been widely used in the social and behavioral sciences (for overview, see Idler \& Benyamini, 1997). Data on self-rated health were available in 1994 only and was used as both as a correlate in our antecedent analyses and as a covariate in our outcomes analyses.

Social participation was measured using a 4-item index given on six occasions $(1985,1986$, $1988,1990,1992$, and 1994) assessing participants' frequency of involvement in or attendance at social networking and community activities, including politics, honorary activities in clubs/groups, sports, and attendance of cultural events. The Appendix contains the social participation items as administered in German and their corresponding English translation. The scale is highly similar in structure to other instruments being used to assess social participation (see Parslow, Jorm, Christensen, \& Mackinnon, 2006). The social participation items that were endorsed most frequently were sport activities and honorary/ cultural activities. Items were reverse coded and averaged to obtain an index with higher scores indicating greater social participation. On average, participants contributed 3.78 (SD $=2.03$ ) social participation observations, with $n=9,297$ or $88.32 \%$ providing two or more repeated measures.

We also made use of a single item religious participation that asked participants, "Wie oft gehen Sie in die Kirche oder besuchen religiöse Veranstaltungen?" ("How often do you attend church or other religious events?"). The item was answered using a 4-point Likert scale $(1=$ every week to $4=$ never ; Headey et al., 2010$)$ and reverse coded such that higher scores indicate more frequent attendance of church or other religious events. Data on religious participation were available in 1994 and used as both as a correlate in our antecedent analyses and as a covariate in our outcomes analyses.

Life satisfaction was measured annually, 1984 to 1994, using the single item, "Wie zufrieden sind Sie gegenwärtig, alles in allem, mit ihrem Leben?" ("How satisfied are you concurrently with your life, all things considered?"). Participants answered on a scale from 0 (totally unsatisfied) to 10 (completely satisfied). This item is considered a measure of cognitive-evaluative aspects of well-being (as opposed to emotional aspects) and has been widely used in psychological research (e.g., Fujita \& Diener, 2005; Gerstorf, Ram, et al., 2008; Lucas, 2007). On average, participants contributed $6.95(S D=3.74)$ longitudinal observations, with $n=9,719$ or $92.33 \%$ providing two or more repeated measures.

We also included socio-demographic variables of gender, education, and income as covariates in both our antecedents and outcomes analyses. Education was measured as total number years of schooling ranging from 7-18 years. Income was obtained from the 
participants and divided into seven categories (for similar procedure, see Lachman \& Weaver, 1998) based on annual household income post government taxes (in Euros): 0 (\$0 thru \$9,999), 1 (\$10,000 thru \$14,999), 2 (\$15,000 thru \$19,999), 3 (\$20,000 thru \$24,999), 4 (\$25,000 thru 34,999), $5(\$ 35,000$ thru $\$ 49,999)$, and 6 (greater than $\$ 50,000)$.

We note that we only utilized single indicators for disability status, health, and life satisfaction. We conducted a secondary data analysis of unique longitudinal data and as a result were unable to include multiple indicators of each domain. In the discussion, we discuss future prospects of utilizing various other facets of health and well-being.

Level and time-related change-Making use of the longitudinal data, we defined level and time-related change constructs for social participation and life satisfaction. To do so, we fit growth curve models (e.g., McArdle \& Nesselroade, 2003; Singer \& Willett, 2003) to the longitudinal data to obtain estimates of the intercept (i.e., level) and linear slope (i.e., timerelated change) of each individual (i.e., Bayes empirical score estimates obtained using SAS PROC MIXED, see Littell, Milliken, Stroup, Wolfinger, \& Schabenberber, 2006). These variables were then used as predictors in subsequent regression models to predict betweenperson differences in perceived control.

The growth curve models were specified as

$$
y_{w i}=\beta_{0 i}+\beta_{1 i} \text { Time }_{w i}+e_{w i}
$$

where $y_{w i}$ is individual $i$ 's social participation or life satisfaction score at wave $w, \beta_{0 i}$ is the individual's estimated level of life satisfaction or social participation in $1994, \beta_{1 i}$, is the individual's implied rate of development over the study period, and $e_{w i}$ are residual errors. Following standard growth curve modeling procedures, individual-specific intercepts, $\beta_{0 i}$ and linear slopes, $\beta_{1 i}$, (from Level 1 model given in Equation 1), were specified as

$$
\begin{aligned}
& \beta_{0 i}=\gamma_{00}+u_{0}, \\
& \beta_{1 i}=\gamma_{01}+u_{1 i},
\end{aligned}
$$

(i.e., Level 2 model) where $\gamma_{00}$, and $\gamma_{01}$ are sample means and $u_{0 i}$ and $u_{1 i}$ are individual deviations from those means. These between-person differences are assumed to be multivariate normally distributed, correlated with each other, and uncorrelated with the residual errors, $e_{w i}$. We applied full information maximum likelihood estimation to all data points available, treating incomplete data as missing at random (Little \& Rubin, 1987).

We note that in constructing these models, our focus was on capturing meaningful betweenperson difference measures of level and time-related change and not necessarily in identifying the best fitting model for the longitudinal data (i.e., not including quadratic and cubic terms in the models, see discussion in Ram \& Gerstorf, 2009a; Ram \& Grimm, 2007; examples in Ram, Gerstorf, Lindenberger, \& Smith, in press). Specifically we used a linearonly "measurement" model because it parsimoniously isolated the relevant between-person differences in change. Reasons for going with the linear-only growth model included multicollinearity (with the linear and quadratic components being highly negatively correlated, $r=-.85$ ), no additional variance in the outcome being explained by an orthogonal quadratic component, and the inherent ambiguity in the interpretation of between-person differences in quadratic change (without extensive reparameterization; see Cudeck \& Dutoit, 2002). In follow-up analyses, we additionally included the quadratic parameter and found substantively similar findings to those reported. 


\section{Statistical Analyses}

Correlates and antecedents of perceived control-To examine correlates and antecedents of perceived control, we estimated four regression models, entering the correlates and antecedents of perceived control in a stepwise fashion. In Model 1, perceived control in 1994 was regressed on level and time-related change in social participation and life satisfaction as well as concurrent religious participation. In Model 2, the health measures were added as predictors; in Model 3, socio-demographic variables were added, followed by all age interaction terms in Model 4.

Health outcomes of perceived control-To examine if perceived control was predictive of 14-year between-person differences in hazards for disability and mortality, we applied hierarchical Cox proportional hazard regression models (Cox, 1972). We modeled the hazards for the events of disability and death for the time interval between 1994 (when perceived control was first assessed) and 2008 using SAS (PROC PHREG, see Allison, 1995). Scores for perceived control, life satisfaction, social and religious participation, and self-rated health were z standardized $(M=0, S D=1)$ so that the hazard ratios (HR) reported in Tables 3 and 4 are interpreted with respect to $1 S D$ change. Specifically, we estimated three models in a stepwise fashion to examine (1) if perceived control was a significant predictor of hazard rates for disability or mortality, (2) if the predictive effects were independent of socio-demographic variables, and (3) if these effects were robust beyond the effects of other psychosocial factors. As a conservative test for the uniqueness of associations, our disability models covary for the effects of mortality and in parallel our mortality models covary for the effects of disability. In Models 2 and 3, we also included interaction terms of age with all other predictors to examine if the noted effects were moderated by age and to address the age-differential relevance of perceived control for disability and mortality. Model 2 was specified as

$$
\begin{aligned}
\log h\left(t_{i j}\right) & =\log h_{0}\left(t_{j}\right) \\
& +\beta_{1}\left(\text { control }_{i}\right) \\
& +\beta_{2}\left(\operatorname{age}_{i}\right) \\
& +\beta_{3}\left(\text { education }_{i}\right) \\
& +\beta_{4}\left(\text { gender }_{i}\right) \\
& +\beta_{5}\left(\text { income }_{i}\right) \\
& +\beta_{6}\left(\operatorname{age}_{i} \times \text { control }_{i}\right) \\
& +\beta_{7}\left(\operatorname{age}_{i} \times \text { education }_{i}\right) \\
& +\beta_{8}\left(\operatorname{age}_{i} \times \text { gender }_{i}\right) \\
& +\beta_{9}\left(\text { age }_{i} \times \text { income }_{i}\right)
\end{aligned}
$$

In equation $2, \log h\left(t_{i j}\right)$ is the $\log$ of individual $i$ 's risk of becoming disabled or dying (or log hazard: $\log h$ ) at time $t$. $\log h_{0}\left(t_{j}\right)$ is the general baseline $\log$ hazard function, which is the risk of becoming disabled or dying at each time when all other predictors are set to $0 . \beta_{1}$ through $\beta_{5}$ indicate the independent effects of perceived control, age, education, gender, and income on the hazard of becoming disabled or dead, and $\beta_{6}$ through $\beta_{9}$ indicate the extent to which age moderated those effects. Of particular interest here are the effects of perceived control and the perceived control by age interaction, $\beta_{1}$ and $\beta_{6}$. 


\section{Results}

\section{Correlates and Long-Term Antecedents of Perceived Control}

Table 2 shows results from our regression models examining between-person differences in perceived control. Results from Model 1 suggest that concurrent level and time-related change in social participation were predictive of perceived control. Participants with greater engagement as well as those who experienced more favorable changes in social participation were more likely to report higher perceived control. Additionally, levels of life satisfaction and religious participation, but not time-related change in life satisfaction were related to perceived control. Panels A and B of Figure 2 graphically show that participants reporting higher levels of social participation and life satisfaction, on average, were more likely to report higher levels of perceived control. At the bottom of Table 2, we observed that components of social participation and life satisfaction, in addition to religious participation accounted for $13 \%$ of the variance in perceived control.

In model 2, we included correlates and antecedents representing the health domain as predictors of between-person differences in perceived control. Model 2 indicates that selfrated health, but not disability status was predictive of perceived control. This suggests that perceptions of one's health provides unique albeit little (1\%) additional variance to the prediction of perceived control.

In model 3, we additionally included socio-demographic variables. We found independent associations of each socio-demographic variable to perceived control, suggesting that older age, being a woman, fewer years of education, and lower income were all related to lower perceived control. Socio-demographic variables accounted for an additional $6 \%$ of the variance in perceived control.

In our final Model 4, we added age interaction effects. To begin with, the effects of social participation, life satisfaction, religious participation, and self-rated health again remained statistically significant. We also found three significant age interactions.1 First, the age by gender interaction suggests that the gender difference in perceived control is less pronounced in older ages, with older women having a lower risk for lower perceived control. Second, we found the age by level and time-related change in life satisfaction interactions were reliably different from zero, indicating that older participants reporting higher levels of, as well as those experiencing more favorable changes in life satisfaction over time tended to report more perceived control.

\section{Health Outcomes of Perceived Control}

Results from hierarchical Cox proportional hazard regression models using perceived control to predict 14-year incidence rates of disability are shown in Table 3. In Model 1, we found that perceived control was predictive of the hazard for disability at the zero-order level. A one standard deviation increase in perceived control related to an approximately $2 \%$ lower hazard for disability. Panel A of Figure 3 illustrates that SOEP participants who perceived more control were at lower risks for developing disability. 2 Next, Model 2 additionally included socio-demographic variables and the corresponding age interaction terms. Perceived control did not provide a unique contribution to the hazard of disability that was independent of socio-demographic variables. Similar patterns of results were obtained in Model 3 when we included psychosocial factors and the corresponding age interaction

\footnotetext{
${ }^{1}$ In our final Model 4 we report only age interactions where the standardized beta was larger than .03. Given the large sample size, this was done to minimize any spurious age interaction findings. Also, substantively similar findings were observed when we included a similar religion item in place of religious participation that asked participants about the importance of religion and faith.

${ }^{2}$ Panels A and B in Figure 3 were created using the Kaplan Meier method at the zero-order level.
} 
terms as additional predictors. In these analyses, only self-related health and older age at death emerged as significant predictors of disability hazards.

Table 4 presents findings from hierarchical Cox regression models that examined the association of perceived control for mortality hazards. In Model 1, we found that greater perceived control predicted a lower hazard for mortality. Each one standard deviation increase in perceived control related to an approximately 5\% decreased likelihood of death. Panel B of Figure 3 illustrates that SOEP participants with greater perceived control were at lower risks for dying. In Model 2, we additionally included socio-demographic variables and the corresponding age interaction terms. In contrast to the disability analyses, both perceived control and the control by age interaction remained significant predictors of mortality. Results suggest that the predictive effects of perceived control for risk of mortality were stronger in older age. In model 3, we observed that the main effect of control remained significant, net of socio-demographic and psychosocial factors, whereas the control by age interaction was attenuated to the null. Independent of socio-demographic and psychosocial factors, each one standard deviation increase in perceived control was associated with a $4 \%$ decreased likelihood of death. Our findings show that perceived control provides unique predictive ability over and above known correlates of mortality. Other significant predictors of hazard of mortality included: Older age, being a man, being an older man, lower income, having reported lower social participation, having lower social participation in old age, poorer self-rated health, and poorer self-rated health in old age.

\section{Discussion}

The objective of our study was to utilize 25-year data from the SOEP to examine long-term antecedents, correlates, and outcomes of perceived control across adulthood and old age. Targeting correlates and antecedents of control, multiple regression analyses indicated that higher levels of social participation, life satisfaction, and self-rated health were each uniquely predictive of perceived control. Perceived control was also independently related to more positive changes in social participation over the preceding 11 years. Targeting health outcomes of control, our survival analyses revealed that perceived control predicted 14-year hazards for disability and mortality at the zero-order level. The effect for mortality, but not for disability, was independent of socio-demographic and psychosocial factors. Overall, we found very limited support for age-differential associations for antecedents and consequents of perceived control. We discuss that perceived control is embedded in various systems of influence and how these may or may not differ across adulthood and old age.

\section{Correlates and Long-Term Antecedents of Perceived Control}

Our first objective was to examine correlates and long-term antecedents of control. To do so, we conjointly targeted the role of social, well-being, and health domains as well as sociodemographic variables for between-person differences in perceived control. Our results indicated that concurrent level and time-related change in social participation were predictive of perceived control. These findings are consistent with theoretical accounts and empirical reports highlighting the role of the social environment for building, maintaining, and enlarging feelings of efficacy and control (Antonucci \& Jackson, 1987; Bandura, 1977; Krause, 1987; Lang et al., 1997). From a conceptual viewpoint, it has been argued that observing a network member enacting a certain workout regimen enhances one's own sense of efficacy to carry out and persist with the regimen (Bandura, 1997). In addition, the effect of social participation may not only reflect a sense of efficacy as derived from social activity, but also index better access to social capital (Lin, 2001; Moren-Cross \& Lin, 2006). For example, actively participating within clubs/groups or social service organizations may provide individuals with access to resources of their social network (e.g., information, reinforcement of certain behaviors), which in turn can be used to exercise control over 
attaining desired outcomes. In a similar vein, increasing community participation or continual interaction with network members over time reinforces and strengthens an individual's beliefs about exercising control. In contrast, disengagement from social participation over time restrains the amount of encouragement and positive feedback an individual receives for completing particular tasks. Also, we found that more frequent attendance of church or religious events was associated with lower levels of perceived control. It is conceivable that religious beliefs are instead related to greater feelings of external control and powerful others. Overall, our findings illustrate the role of various participation variables for perceptions of control, but it is upon future research to pinpoint the specific sources and dimensions carrying those effects. It may be of particular interest to examine the role that anticipated, enacted, and exchanged forms of support (and their combination) play for perceived control (see Krause, 2003).

We also found that higher levels of life satisfaction were related to more perceived control. Empirically, our findings are similar to and extend McAvay and colleagues (1996) who reported that depression was associated with levels and subsequent declines in domainspecific self-efficacy. Conceptually, one could argue that feeling greater joy over life relates to perceiving that one's actions, choices, and efforts can shape the environment for the attainment of successful outcomes (Lyubomirsky, King, \& Diener, 2005). In contrast, compromised well-being may undermine perceptions of control so that individuals with low well-being may not utilize their opportunities to actually exert control.

We also tested several health variables as correlates and antecedents of perceived control. Self-rated health emerged as a consistent predictor of perceived control; individuals with a more favorable appraisal of their health were more likely to report more control. One possible mechanism may be that individuals who appraise their health to be very good or excellent may perceive fewer external constraints. For example, more positive assessments of one's own health are related to feeling that one has the means for making a change or adapt to a challenging life situation. Another possible mechanism is that individuals with more positive perceptions of their health are motivated to maintain their health through adopting and persevering with healthy behaviors. For example, positive assessments of one's health may be related to maintaining beliefs that one's health behaviors are indeed linked with attaining positive health outcomes. In contrast to our expectation, perceived control was not related to concurrent disability status. One interpretation is that this finding is indicative of the power of self-resilient processes, even in the face of major physical limitations. We note, however, that health is a multidimensional construct and the overlap between objective, subjective, and functional measures of health is typically only of moderate size (Steinhagen-Thiessen \& Borchelt, 1999). Thus, it would be informative to test if differential associations with perceived control emerge for those indicators.

In line with results from cross-sectional and longitudinal studies, we observed that younger age, more education, income, and being a man, were each predictive of higher levels of perceived control (Mirowsky, 1995). More specifically, Ross and Mirowsky (2002) argued that with age, people increasingly perceive that changes in the environment are less contingent upon their own actions, beliefs, and choices, thereby creating and amplifying impressions of constraints and powerlessness. Empirically, extant research suggests that older adults report lower personal mastery, whereas reports of perceived constraints are more common among older adults (Lachman, Rosnick, \& Röcke, 2009). We also found that more educated participants and those with higher income reported more perceived control. Higher education and income are often associated with better access to and availability of resources (e.g., autonomy on the job, ability to achieve goals and solve problems), which in turn foster experiences of mastery (Lachman \& Weaver, 1998; Ross \& Mirowsky, 2002). The gender difference found in levels of perceived control is consistent with conceptual 
notions highlighting lifetime disadvantages in work and economic conditions as well as fewer employment and educational opportunities for women (Ross \& Mirowsky, 2002). It is well possible that better access to education among women in later-born cohorts and the changing landscape of the workforce may minimize the purported gender gap in perceived control in the future.

Of the ten age interactions tested in our regression analyses, only three terms were found reliably different from zero. First, the age by gender interaction suggests that gender disparities in perceived control are less pronounced in older ages. Our findings are inconsistent with previous work and may reflect differential cultural control-gender links. Control-gender associations may differ across culture, and future work is needed to thoroughly examine if antecedents show differential effects by culture. Second, the interaction of age with level and time-related change in life satisfaction were significant, which provides preliminary evidence that the well-being domain may be a prime source of control in older ages. Higher levels of and more favorable changes in life satisfaction in older ages may be related to the availability of resources for emotion-focused and goaldirected behavior (Carstensen, Isaacowitz, \& Charles, 1999; Heckhausen et al., 2010). Conversely, given the pervasive stability of well-being indicators across adulthood, it may well be that declines in well-being are indicative of more systemic dysfunctions (e.g., proximate-to-death declines; see Gerstorf, Ram et al., 2010) that also drag perceived control down. Similarly, future work is needed to investigate if and how various other domains of functioning exhibit differential relationships with perceived control across the lifespan. Of particular interest would be to address whether the prime social sources of self-efficacy may operate differently across the adult lifespan (e.g., spouse, friends, and colleagues in midlife vs. spouse and adult children in old age; see Krause, 2003). In a similar vein, the various dimensions of health such as health conditions and performance-based measures of walking ability may exhibit differentially strong associations with perceived control (e.g., "on-time" events in old age vs. "off-time" events in midlife; Neugarten \& Hagestad, 1976).

\section{Health Outcomes of Perceived Control}

Our main findings were that perceived control predicted hazards of both disability and mortality and that the predictive effects for mortality, but not disability, were net of sociodemographic and psychosocial factors. These results are in line with earlier reports documenting that perceived control has implications for a variety of different health outcomes (Caplan \& Schooler, 2003; Femia et al., 1997; Gerstorf et al., 2011; Hall, Chipperfield, Heckhausen, \& Perry, 2010; Mendes de Leon, Seeman, Baker, Richardson, \& Tinetti, 1996; Seeman et al., 1999). For example, research has shown that facets of control are predictive of mortality over a period ranging from 2.5 years (Penninx et al., 1997) to 11 years (Surtees et al., 2010). Our study adds to this research by targeting these associations over an even longer time frame of 14 years and by examining possible age differential relations.

It is unclear which mechanisms underlie the health implications of perceived control, but theoretical notions primarily highlight the role of health behaviors, stress reactivity, emotion regulation, and social support (Lachman, 2006; Rodin, 1986). As a first possible pathway, perceived control may reduce the risk of developing poor health because individuals who report more control beliefs are more likely to practice and take part in health maintenance behaviors such as exercise and preventive care (Rodin, 1986; Seeman et al., 1999). Second, perceived control is known to buffer the negative impact of stressors on emotional and physiological reactivity (Kunz-Ebrecht, Kirschbaum, \& Steptoe, 2004). For example, reports from the National Study of Daily Experiences show that lower personal control was related to increases in emotional distress and physical health symptoms to stressors (Neupert, Almeida, \& Charles, 2007). In turn, a lack of effective coping resources to stressors can alter 
physiological functioning (e.g., dysregulation of the HPA axis), resulting in increasing the risk for accumulating diseases (Cohen, 2000).

As a third potential pathway, perceived control is known to be involved in emotion regulation (Lang \& Heckhausen, 2001). For example, more perceived control allows people to better down regulate negative emotional experiences, thereby alleviating the detrimental effects of negative emotions on cardiovascular and immune functioning (Danner, Snowdon, \& Friesen, 2001; Pressman \& Cohen, 2005). Finally, various theories of control (e.g., Heckhausen \& Schulz, 1995) argue that control beliefs allow people to mobilize social support, particularly in times of strain, thereby serving as a buffer against the effects of stress (see Antonucci, 2001; Cohen \& Wills, 1985; Lang et al., 1997). It was beyond the immediate scope and possibilities of our study to explore these and other possible mechanisms, so future studies are warranted to pinpoint the role these domains play for the health implications of perceived control. Rather than using panel survey data alone, one promising avenue would be integrated studies that link development across different time scales. For example, daily-diary designs have shown that people who perceive more control and show little week-to-week variability therein also rate the availability of others and their well-being more favorably and more consistent (Lang et al., 1997; Reis, Sheldon, Gable, Roscoe, \& Ryan, 2000). Measurement burst designs (for discussions, see Ram \& Gerstorf, 2009b; Nesselroade, 1991) that embed such micro-time research designs within more macro-time designs have the potential to inform us about how the discussed effects of health behaviors, stress reactivity, emotion regulation, and social support accumulate over time and interact with perceptions of control.

Our results at the zero-order level indicated that the predictive effects of perceived control for mortality were stronger in older ages, but the effect completely vanished in our final model when additional covariates were taken into account. These findings thus provide very limited support for conceptual notions suggesting that the effects of perceived control are more visible in later phases of life relative to earlier phases (see Elder \& Johnson, 2003; Infurna et al., in press). We expected that the beneficial or detrimental consequences of control would accumulate across adulthood and progressively turn into more immediate and proximal outcomes with advancing age. Conceptual arguments for such lifetime continuity have been supported by two sets of empirical reports. First, locus of control in childhood has been found to predict health behaviors and weight status at age 30 (Gale et al., 2008). Second, health behaviors in young adulthood such as excessive drinking, smoking, and obesity have repeatedly been found to predict health outcomes in old age, including disability and mortality (Friedman et al., 1995; Vaillant \& Mukamel, 2001). In addition, average health conditions during the midlife years may not be serious enough or evince sufficient between-person heterogeneity for statistical models to pick up. To further test this conceptual reasoning, future more mechanism-oriented work is needed to examine whether age differences and age-associated changes exist amongst perceived control and its mechanisms of influence.

\section{Limitations and Outlook}

We note several limitations in our study. First, despite targeting long-term antecedents, correlates, and outcomes of perceived control conjointly in one study, we cannot draw any causal inferences from our large-scale panel study. At most, we can draw preliminary inferences regarding the temporal ordering of developmental change. As indicated in Lachman's (2006) conceptual framework, and shown empirically in our study, perceived control serves as both a predictor of health outcomes in adulthood and old age and a consequence of resources in other pivotal areas of functioning. For example, our antecedent analyses revealed that preceding 11-year change in social participation were predictive of between-person differences in perceived control. However, the temporal direction may also 
be reversed with perceived control being an antecedent of changes in social activities (Lachman et al., 2009). We also note that control and facets of well-being show timeordered associations in the opposite direction to the one tested in our study, such that perceived control may precede and predict subsequent changes in well-being (Röcke \& Lachman, 2008). Applications of dynamic models promise to provide insights into the timeordering of associations between developmental changes among perceived control and the social, well-being, and health domains to further advance and refine conceptual models of perceived control (cf. Infurna et al., in press).

Second, our disability measure considerably differed from the typical self-reports of limitations in Activities of Daily Living (Katz et al., 1963). Our index referred to having a reduced capacity to work or being certified as severely handicapped, which may have been too conservative to detect discernable differences. We note, however, that our measure has successfully been used in several earlier studies to examine disability-related questions (e.g., lasting well-being changes resulting from disability; Lucas, 2007). Also, the temporal ordering targeted in our study is just one of several possible. For example, if longitudinal control data were available, changes in control could be aligned in relation to the onset of disability. For example, it is conceivable that perceived control considerably declines with the accumulation of disability.

Third, the SOEP does not yet have access to cause of death information; thus, we were only able to examine all-cause mortality. Recent work by Surtees and colleagues $(2006,2010)$ showed that perceived control was related to cardiovascular mortality, but not to cancer mortality. These findings shed light on possible differential mechanisms involved in controlmortality outcomes. To further test such hypotheses, future work would benefit from examining targeting the specific mechanism underlying such associations and also how perceived control relates to mortality from other causes such as diabetes or respiratory diseases. Finally, we only examined levels of perceived control. We thus cannot draw any inferences whether age or time-related changes in perceived control predict health outcomes (Eizenman, Nesselroade, Featherman, \& Rowe, 1997) or reversely which factors contribute to age-related changes in perceived control (Mirowsky \& Ross, 2007).

In closing, our results highlight the importance of taking a multivariate stance at better understanding factors related to and implications arising from perceptions of control across adulthood and old age. Our study adds to extant reports showing that perceived control is an integral component of adult development and aging (Bandura, 1997; Heckhausen \& Schulz, 1995; Lachman, 2006). We take our results to provide impetus to develop long-term longitudinal studies, like SOEP, further by adding new measurement devices (i.e., biomarkers), which will allow for thoroughly examining processes involved in antecedentconsequent relations of perceived control to facets of social life, well-being, and health.

\section{Acknowledgments}

Denis Gerstorf and Nilam Ram gratefully acknowledge the support provided by the National Institute on Aging (NIA) RC1-AG035645; NIA R21-AG032379; and NIA R21-AG033109; the DIW Berlin (German Institute for Economic Research); and the Social Science Research Institute at the Pennsylvania State University. Additional support was provided by a grant from the Bundesministerium für Bildung und Forschung (Germany) to Jürgen Schupp and Gert G. Wagner (BMBF-DLR 01UW0706) and Gert G. Wagner's Max Planck Fellowship Society.

\section{References}

Aldwin, CM.; Spiro, A., III; Park, CL. Health, behaviors, and optimal aging: A lifespan developmental perspective. In: Birren, JE.; Schaie, KW., editors. Handbook of the psychology of aging. 6th ed.. San Diego, CA: Elsevier; 2006. p. 85-104. 
Allison, PD. Survival analysis using the SAS (R) system: A practical guide. Cary, NC: SAS Institute; 1995.

Antonucci, TC. Social relations: An examination of social networks, social support, and sense of control. In: Birren, JE.; Schaie, KW., editors. Handbook of the psychology of aging. San Diego, CA: Academic Press; 2001. p. 427-453.

Antonucci, TC.; Jackson, JS. Social support, interpersonal efficacy and health. In: Carstensen, LL.; Edelstein, BA., editors. Handbook of clinical gerontology. New York, NY: Pergamon; 1987. p. 291-311.

Baltes, MM.; Baltes, PB. The psychology of control and aging. Hillsdale, NJ: Erlbaum; 1986.

Bandura A. Self-efficacy: Toward a unifying theory of behavioral change. Psychological Review. 1977; 84:191-215. [PubMed: 847061]

Bandura, A. Self-efficacy: The exercise of control. New York: Freeman; 1997.

Brandtstädter J, Greve W. The aging self: Stabilizing and protective processes. Developmental Review. 1994; 14:52-80.

Caplan LJ, Schooler C. The roles of fatalism, self-confidence, and intellectual resources in the disablement process in older adults. Psychology and Aging. 2003; 18:551-561. [PubMed: 14526765]

Cairney J, Corna LM, Wade T, Streiner DL. Does greater frequency of contact with general physicians reduce feelings of mastery in older adults? Journals of Gerontology: Series B Psychological Sciences. 2007; 62B:P226-P229.

Carstensen LL, Isaacowitz DM, Charles ST. Taking time seriously: A theory of socioemotional selectivity. American Psychologist. 1999; 54:165-181. [PubMed: 10199217]

Centers for Disease Control and Prevention, National Center for Injury Prevention and Control. [2010 September 14] Web-based Injured Statistics Query and Reporting System (WISQARS). 2005. [online]. Available from URL: www.cdc.gov/ncipc/wisqars

Cohen HJ. In search of the underlying mechanisms of frailty. Journal of Gerontology: Medical Sciences. 2000; 55A:M706-M708.

Cohen S, Wills TA. Stress, social support, and the buffering hypothesis. Psychological Bulletin. 1985; 98:310-357. [PubMed: 3901065]

Cox DR. Regression models and life tables. Journal of the Royal Statistical Society Series B (Methodological). 1972; 34:187-220.

Crimmins EM, Alley D, Reynolds SL, Johnston M, Karlamangla A, Seeman E. Changes in biological markers of health: Older Americans in the 1990s. Journals of Gerontology, Series A: Medical Sciences. 2005; 60A:1409-1413.

Cudeck R, du Toit SHC. A version of quadratic regression with interpretable parameters. Multivariate Behavioral Research. 2002; 37:501-519.

Danner DD, Snowdon DA, Friesen WV. Positive emotions in early life and longevity: Findings from the Nun Study. Journal of Personality and Social Psychology. 2001; 80:804-813. [PubMed: 11374751]

Deci, EL.; Ryan, RM. Human autonomy: The basis for true self-esteem. In: Kernis, M., editor. Efficacy, agency, and self-esteem. New York, NY: Plenum Press; 1995. p. 31-49.

Eizenman DR, Nesselroade JR, Featherman DL, Rowe JW. Intraindividual variability in perceived control in an older sample: The MacArthur Successful Aging Studies. Psychology and Aging. 1997; 12:489-502. [PubMed: 9308096]

Elder, GH., Jr; Johnson, KM. The life course and aging: Challenges, lessons, and new directions. In: Settersten, RA., Jr, editor. Invitation to the life course: Towards new understandings of later life. Amityville, NY: Baywood; 2003. p. 49-81.

Fauth EB, Zarit SH, Malmberg B, Johansson B. Physical, cognitive, and psychosocial variables from the disablement process model predict patterns of independence and the transition into disability for the oldest-old. The Gerontologist. 2007; 47:613-624. [PubMed: 17989403]

Feingold A. Gender differences in personality: A meta-analysis. Psychological Bulletin. 1994; 116:429-456. [PubMed: 7809307] 
Femia EE, Zarit SH, Johansson B. Predicting change in activities of daily living: A longitudinal study of the oldest old in Sweden. Journal of Gerontology: Psychological Sciences. 1997; 52B:P294P302.

Friedman HS, Tucker JS, Schwartz JE, Tomlinson-Keasey C, Martin LR, Wingard DL, et al. Psychosocial and behavioral predictors of longevity: The aging and death of the "Termites". American Psychologist. 1995; 50:69-78. [PubMed: 7879989]

Fujita F, Diener E. Life satisfaction set point: Stability and change. Journal of Personality and Social Psychology. 2005; 88:158-164. [PubMed: 15631581]

Fung, HH.; Abeles, RP.; Carstensen, LL. Psychological control in later life: Implications for life-span development. In: Brandstädter, J.; Lerner, RM., editors. Action \& self-development: Theory and research through the lifespan. Thousand Oaks, CA: Sage; 1999. p. 345-372.

Gale CR, Batty GD, Deary IJ. Locus of control at age 10-years and health outcomes and behaviors at age 30 years: the 1970 British Cohort Study. Psychosomatic Medicine. 2008; 70:397-403. [PubMed: 18480188]

Gerstorf D, Ram N, Estabrook R, Schupp J, Wagner GG, Lindenberger U. Life satisfaction shows terminal decline in old age: Longitudinal evidence from the German Socio-Economic Panel study (SOEP). Developmental Psychology. 2008; 44:1148-1159. [PubMed: 18605841]

Gerstorf D, Ram N, Mayraz G, Hidajat M, Lindenberger U, Wagner GG, Schupp J. Late-life decline in well-being across adulthood in Germany, the United Kingdom, and the United States: Something is seriously wrong at the end of life. Psychology and Aging. 2010; 25:477-485. [PubMed: 20545432]

Gerstorf D, Röcke C, Lachman ME. Antecedent-consequent relations of perceived control to health and social support: Longitudinal evidence for between-domain associations across adulthood. Journals of Gerontology, Series B: Psychological Sciences. 2011; 66B:61-71.

Hall NC, Chipperfield JG, Heckhausen J, Perry RP. Control striving in older adults with serious health problems: A 9-year longitudinal study of survival, health, and well-being. Psychology and Aging. 2010; 25:432-435. [PubMed: 20545427]

Headey B, Schupp J, Tucci I, Wagner GG. Authentic happiness theory supported by impact of religion on life satisfaction: A longitudinal analysis with data for Germany. The Journal of Positive Psychology. 2010; 5:73-82.

Headey B, Muffels R, Wagner GG. Long-Running German Panel Survey Shows That Personal and Economic Choices, Not Just Genes, Matter for Happiness. PNAS (Proceedings of the Academy of Sciences of the United States of America). 110 (in press).

Heckhausen J, Schulz R. A life-span theory of control. Psychological Review. 1995; 102:284-304. [PubMed: 7740091]

Heckhausen J, Wrosch C, Schulz R. A motivational theory of life-span development. Psychological Review. 2010; 117:32-60. [PubMed: 20063963]

Idler EL, Benyamini Y. Self-rated health and mortality: A review of twenty-seven community studies. Journal of Health and Social Behavior. 1997; 38:21-37. [PubMed: 9097506]

Infurna FJ, Gerstorf D, Zarit SH. Examining dynamic links between perceived control and health: Longitudinal evidence for differential linkages in midlife and old age. Developmental Psychology. (in press).

Katz S, Ford AB, Moskowitz RW, Jackson BA, Jaffe MW. Studies of illness and the aged. The index of ADL: A standardized measure of biological and psychosocial function. Journal of the American Medical Association. 1963; 185:914-923. [PubMed: 14044222]

Klein, T. Determinants of institutionalization in old age. In: Eisen, R.; Sloan, F., editors. Long-term care: Economic issues and policy solution. Boston, MA: Kluwer; 1996. p. 103-113.

Krause N. Understanding the stress process: Linking social support with locus of control beliefs. Journal of Gerontology. 1987; 42:589-593. [PubMed: 3680876]

Krause, N. The social foundations of personal control in late life. In: Zarit, SH.; Pearlin, LI.; Schaie, KW., editors. Personal control in social and life course contexts. New York: Springer; 2003. p. 45-70.

Krause N. Age and decline in role-specific feelings of control. Journals of Gerontology: Social Sciences. 2007; 62B:S28-S35. 
Krause N, Shaw BA. Role-specific feelings of control and mortality. Psychology and Aging. 2000; 15:617-626. [PubMed: 11144321]

Kroh, M.; Spiess, M. Documentation of sample sizes and panel attrition in the Socio Economic Panel (SOEP) (1984 until 2005). Berlin: 2006. DIW Data Documentation No. 15.

Kroh M, Pischner R, Spiess M, Wagner GG. On the treatment of non-original sample members in the German Household Panel Study (SOEP): Tracing and weighting. Methoden - Daten - Analysen. 2008; 2:179-198.

Kunz-Ebrecht SR, Kirschbaum C, Steptoe A. Work stress, socioeconomic status and neuroendocrine activation over the working day. Social Science Medicine. 2004; 58:1523-1530. [PubMed: 14759695]

Kunzmann U, Little TD, Smith J. Perceiving control: A double-edged sword in old age. Journals of Gerontology Series B-Psychological Sciences \& Social Sciences. 2002; 57:P484-P491.

Lachman ME. Perceived control over aging-related declines: Adaptive beliefs and behaviors. Current Directions in Psychological Science. 2006; 15:282-286.

Lachman, ME.; Firth, KM. The adaptive value of feeling in control during midlife. In: Brim, OG., Jr; Ryff, CD.; Kessler, RC., editors. How healthy are we?: A national study of well-being at midlife. Chicago, IL: University of Chicago Press; 2004. p. 320-349.

Lachman ME, Weaver SL. The sense of control as a moderator of social class differences in health and well-being. Journal of Personality and Social Psychology. 1998; 74:763-773. [PubMed: 9523418]

Lachman, ME.; Rosnick, CB.; Röcke, C. The rise and fall of control beliefs and life satisfaction in adulthood: Trajectories of stability and change over ten years. In: Bosworth, HB.; Hertzog, C., editors. Aging and cognition: Research methodologies and empirical advances. Decade of behavior (2000-2010). Washington, DC: American Psychological Association; 2009. p. 143-160.

Lang FR, Featherman DL, Nesselroade JR. Social self-efficacy and short-term variability in social relationships: The MacArthur Successful Aging Studies. Psychology and Aging. 1997; 12:657666. [PubMed: 9416633]

Lang FR, Heckhausen J. Perceived control over development and subjective well-being: Differential benefits across adulthood. Journal of Personality and Social Psychology. 2001; 81:509-523. [PubMed: 11554650]

Levenson, H. Differentiating among internality, powerful others, and chance. In: Lefcourt, HM., editor. Research with the locus of control construct. Vol. Vol. 1. New York, NY: Academic Press; 1981. p. 15-63.

Littell, RC.; Miliken, GA.; Steoup, WW.; Wolfinger, RD.; Schabenberger, O. SAS for mixed models. 2nd ed.. Cary, NC: SAS Institute; 2006.

Lin, N. Social capital. Cambridge: Cambridge University Press; 2001.

Little, RJA.; Rubin, DB. Statistical analysis with missing data. New York: Wiley; 1987.

Lucas RE. Long-term disability is associated with lasting changes in subjective well-being: Evidence from two national representative longitudinal studies. Journal of Personality and social Psychology. 2007; 92:717-730. [PubMed: 17469954]

Lyubomirsky S, King L, Diener E. The benefits of frequent positive affect: Does happiness lead to success? Psychological Bulletin. 2005; 131:803-855. [PubMed: 16351326]

McArdle, JJ.; Nesselroade, JR. Growth curve analysis in contemporary psychological research. In: Shinka, J.; Velicer, W., editors. Comprehensive handbook of psychology: Research methods in psychology. Vol. Vol. 2. New York, NY: Wiley; 2003. p. 447-480.

McAvay GJ, Seeman TE, Rodin J. A longitudinal study of change in domain-specific self-efficacy among older adults. Journal of Gerontology: Psychological Sciences. 1996; 51:P243-P253.

Mendes de Leon CF, Seeman TE, Baker DI, Richardson ED, Tinetti ME. Self-efficacy, physical decline and change in functioning in community-living elders: A prospective study. Journal of Gerontology: Social Sciences. 1996; 51B:S183-S190.

Mirowsky J. Age and the sense of control. Social Psychology Quarterly. 1995; 58:31-43.

Mirowsky J, Ross CE. Life-course trajectories of perceived control and their relationship to education. American Journal of Sociology. 2007; 112:1339-1382. 
Moren-Cross, J.; Lin, N. Social networks and health. In: Binstock, RH.; George, LK., editors. Handbook of aging and the social sciences. San Diego, CA: Academic Press; 2006. p. 111-126.

Nesselroade, JR. The warp and woof of the developmental fabric. In: Downs, R.; Liben, L.; Palermo, D., editors. Visions of development, the environment, and aesthetics: The legacy of Joachim F. Wohlwill. Hillsdale, NJ: Erlbaum; 1991. p. 213-240.

Neugarten, BL.; Hagestad, GO. Age and the life course. In: Binstock, RE.; Shanas, E., editors. Handbook of aging and social sciences. New York: Van Nostrand Reinhold; 1976.

Neupert SD, Almeida DM, Charles ST. Age differences in reactivity to daily stressors: The role of personal control. Journal of Gerontology: Psychological Sciences. 2007; 62B:P216-P225.

Parslow RA, Jorm AF, Christensen H, Mackinnon A. An instrument to measure engagement in life: Factor analysis and associations with sociodemographic, health and cognition measures. Gerontology. 2006; 52:188-198. [PubMed: 16645300]

Pearlin LI, Menaghan EG, Lieberman MA, Mullan JT. The stress process. Journal of Health and Social Behavior. 1981; 22:337-356. [PubMed: 7320473]

Pearlin LI, Nguyen KB, Schieman S, Milkie MA. The life-course origins of mastery among older people. Journal of Health and Social Behavior. 2007; 48:164-179. [PubMed: 17583272]

Pearlin LI, Schooler C. The structure of coping. Journal of Health and Social Behavior. 1978; 19:2-21. [PubMed: 649936]

Penninx BWJH, van Tilburg T, Kriegsman DMW, deeg DJH, Boeke AJP, van Eijk J, Th M. Effects of social support and personal coping resources on mortality in older age: The Longitudinal Aging Study Amsterdam. American Journal of Epidemiology. 1997; 146:510-519. [PubMed: 9290512]

Pressman SD, Cohen S. Does positive affect influence health? Psychological Bulletin. 2005; 131:925971. [PubMed: 16351329]

Ram N, Gerstorf D. Methods for the study of development - developing methods. Research in Human Development. 2009a; 62:61-73.

Ram N, Gerstorf D. Time-structured and net intraindividual variability: Tools for examining the development of dynamic characteristics and processes. Psychology and Aging. 2009b; 24:778791. [PubMed: 20025395]

Ram N, Gerstorf D, Lindenberger U, Smith J. Developmental change and intraindividual variability: Relating cognitive aging to cognitive plasticity, cardiovascular lability, and emotional diversity. Psychology and Aging. (in press).

Reis HT, Sheldon KM, Gable SL, Roscoe J, Ryan RM. Daily well-being: The role of autonomy, competence, and relatedness. Personality and Social Psychology Bulletin. 2000; 26:419-435.

Röcke C, Lachman ME. Perceived trajectories of life satisfaction across past, present, and future: Profiles and correlates of subjective change in young, middle-aged, and older adults. Psychology and Aging. 2008; 23:833-847. [PubMed: 19140654]

Rodin J. Aging and health: Effects of the sense of control. Science. 1986; 233:1271-1276. [PubMed: 3749877]

Ross CE, Mirowsky J. Age and the gender gap in the sense of personal control. Social Psychology Quarterly. 2002; 65:125-145.

Rowe JW, Kahn RL. Human aging: Usual and successful. Science. 1987; 237:143-149. [PubMed: 3299702]

Schulz, R.; Heckhausen, J. Emotion and control: A life-span perspective. In: Schaie, KW.; Lawton, MP., editors. Annual review of gerontology and geriatrics, Vol. 17: Focus on emotion and adult development. New York, NY: Springer; 1998. p. 185-205.

Seeman TE, Singer BH, Ryff CD, Love GD, Levy-Storms L. Social relationships, gender, and allostatic load across two age cohorts. Psychosomatic Medicine. 2002; 64:395-406. [PubMed: 12021414]

Seeman TE, Unger JB, McAvay G, Mendes de Leon CF. Self-efficacy beliefs and perceived declines in functional ability: MacArthur Studies of Successful Aging. Journals of Gerontology: Psychological Sciences. 1999; 54B:P214-P222.

Singer, JD.; Willett, JB. Applied longitudinal data analysis: Modeling change and event occurrence. New York, NY: Oxford University Press; 2003. 
Skaff, MM. Sense of control and health: A dynamic duo in the aging process. In: Aldwin, CM.; Park, CL.; Spiro, A., editors. Handbook of health psychology and aging. New York, NY: Guilford; 2007. p. 186-209.

Skinner EA. A guide to constructs of control. Journal of Personality and Social Psychology. 1996; 71:549-570. [PubMed: 8831161]

Steinhagen-Thiessen, E.; Borchelt, M. Morbidity, medication, and functional limitations in very old age. In: Baltes, PB.; Mayer, KU., editors. The Berlin Aging Study: Aging from 70 to 100. New York, NY: Cambridge University Press; 1999. p. 131-166.

Surtees PG, Wainwright NWJ, Luben R, Khaw K-T, Day NE. Mastery, sense of coherence, and mortality: Evidence of independent associations from the EPIC-Norfolk Prospective Cohort Study. Health Psychology. 2006; 25:102-110. [PubMed: 16448303]

Surtees PG, Wainwright WJ, Luben R, Wareham NJ, Bingham S, Khaw K-T. Mastery is associated with cardiovascular disease mortality in men and women at apparently low risk. Health Psychology. 2010; 29:412-420. [PubMed: 20658829]

Uchino BN. Social support and health: A review of physiological processes potentially underlying links to disease outcomes. Journal of Behavioral Medicine. 2006; 29:377-387. [PubMed: 16758315]

Vaillant GE, Mukamal K. Successful aging. American Journal of Psychiatry. 2001; 158:839-847. [PubMed: 11384887]

Wagner GG, Frick JR, Schupp J. Enhancing the power of household panel studies: The case of the German Socio-Economic Panel Study (SOEP). Schmollers Jahrbuch. 2007; 127:139-169.

Weir, D. Elastic powers: The integration of biomarkers into the Health and Retirement Study. In: Weinstein, M.; Vaupel, JW.; Wachter, KW., editors. Committee on Population, Division of Behavioral and Social Sciences and Education, Biosocial Surveys. Washington, DC: The National Academies Press; 2008. p. 78-95.

Wurm S, Tesch-Römer C, Tomasik MJ. Longitudinal findings on aging-related cognitions, control beliefs, and health in later life. Journals of Gerontology: Series B Psychological Sciences. 2007; 62B:P156-P164.

\section{Appendix}

Perceived Control Items in German

Directions:

Die folgenden Aussagen kennzeichnen verschiedene Einstellungen zum Leben und zur Zukunft. In

welchem Maße stimmen Sie persönlich den einzelnen Aussagen zu?

Items:

1. Ich kann ziemlich viel von dem, was in meinem Leben passiert, selbst bestimmen.

2. Planen macht einen Menschen nur unglücklich, da Pläne sich kaum jemals in

die Wirklichkeit

umsetzen lassen.

3. Mein Leben wird von meinem Verhalten bestimmt.

4. Ich meine, keiner kann seinem Schicksal entgehen. Es kommt im Leben

alles, wie es kommen

$\operatorname{mu} \beta$.

5. Wenn ich bekomme, was ich will, so geschieht dies meistens aus Glück.

6. Wenn ich Pläne schmiede, bin ich sicher, daß das Geplante auch 
Wirklichkeit wird.

7. Es hat wenig Sinn, fest umrissene ziele zu verfolgen, weil doch immer etwas Unerwartetes

dazwischenkommt.

8. Es kommt doch immer anders als man denkt, man kann sich auf nichts verlassen.

Response Scale:

Stimme voll zu (1) Stimme eher $\mathrm{zu}$ (2) Stimme eher nicht $\mathrm{zu}$ (3) Stimm überhaupt nicht zu (4)

Perceived Control Items, English Translation

Directions:

The following are various attitudes towards life and the future. Please indicate what most applies to you.

Items :

1. I determine what happens to me in life.

2. It is useless to make plans because they seldom work out.

3. My behavior determines my life.

4. No one can escape their fate, everything in life happens as it must happen.

5. If I get something I want then it's mostly due to luck.

6. Most plans I make are successful.

7. There is little sense in planning ahead because something unexpected always comes up.

8. Things always happen differently, one can't rely on anything.

Response Scale:

Applies completely (1) Applies more or less (2) Does not really apply (3)

Does not apply (4)

Social Participation Items in German

Directions:

Welche der folgenden Tätigkeiten üben Sie in Ihrer freien zeit aus? Geben Sie bitte zu jeder Tätigkeit an, wie oft Sie das machen.

Items :

1. Besuch von kulturellen Veranstaltungen, z.B. Konzerten, Theater, Vorträgen.

2. Aktiver Sport.

3. Ehrenamtliche Tätigkeiten in Vereinen, Verbänden oder sozialen Diensten. 4. Beteiligung in Bürgerinitiativen, in Parteien, in der Kommunalpolitik. Response Scale:

Jede Woche (1) Jeden Monat (2) Seltener (3) Nie (4)

Social Participation Items, English Translation

Psychol Aging. Author manuscript; available in PMC 2012 September 1. 
Directions:

Which of the following activities do you do in your free time? Please enter how often you practice each

activity.

Items :

1. Visit cultural functions, e.g., concerts, theaters, lectures.

2. Active sport participation.

3. Honorary activities in clubs, organizations or social service.

4. Participation in citizen initiatives, parties, community politics.

Response Scale:

Each week (1) Each month (2) Less often (3) Never (4) 


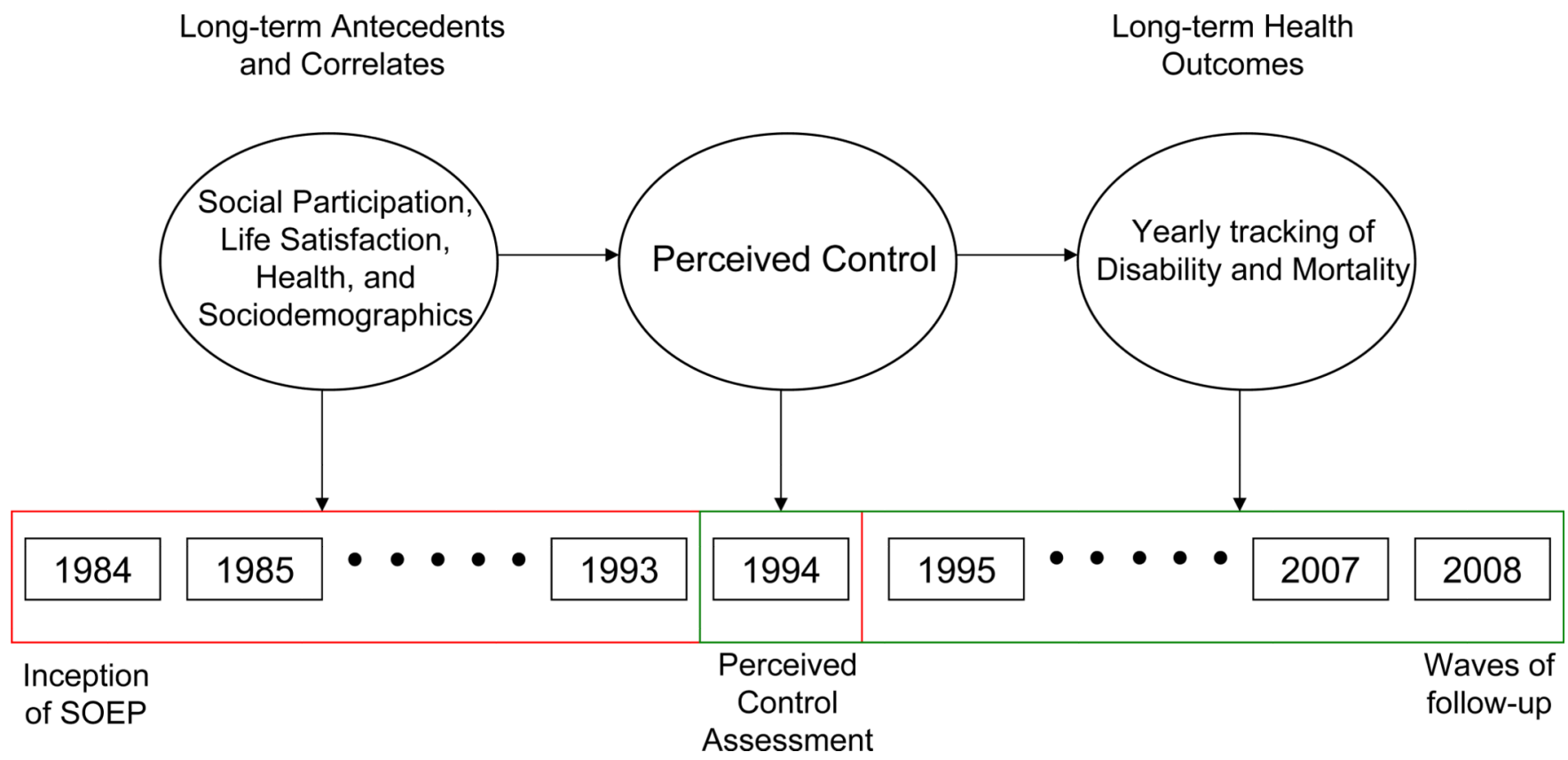

Figure 1.

Overview of data collected in the German Socioeconomic Panel (SOEP) Study, as used in the present study. The SOEP began data collection in 1984 and perceived control was assessed in 1994. For the long-term antecedents and correlates analyses, we utilized data on life satisfaction, social participation, religious participation, health, and demographics that was assessed from 1984 through 1994. For the long-term health outcomes analyses, we utilize perceived control as assessed in 1994 to predict disability and mortality, which were continually tracked from 1994 through 2008. 
(A)

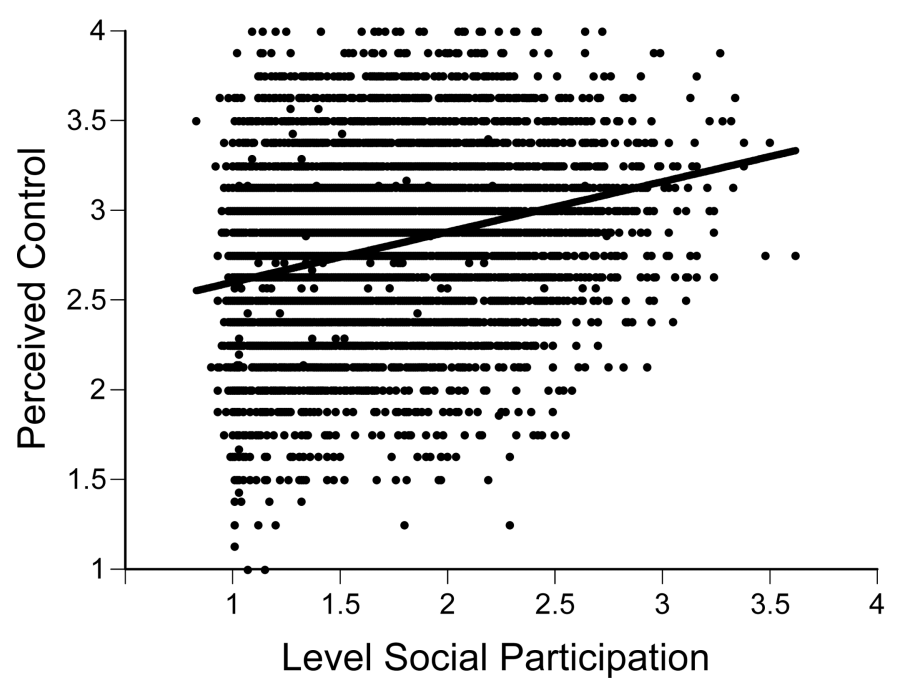

(B)

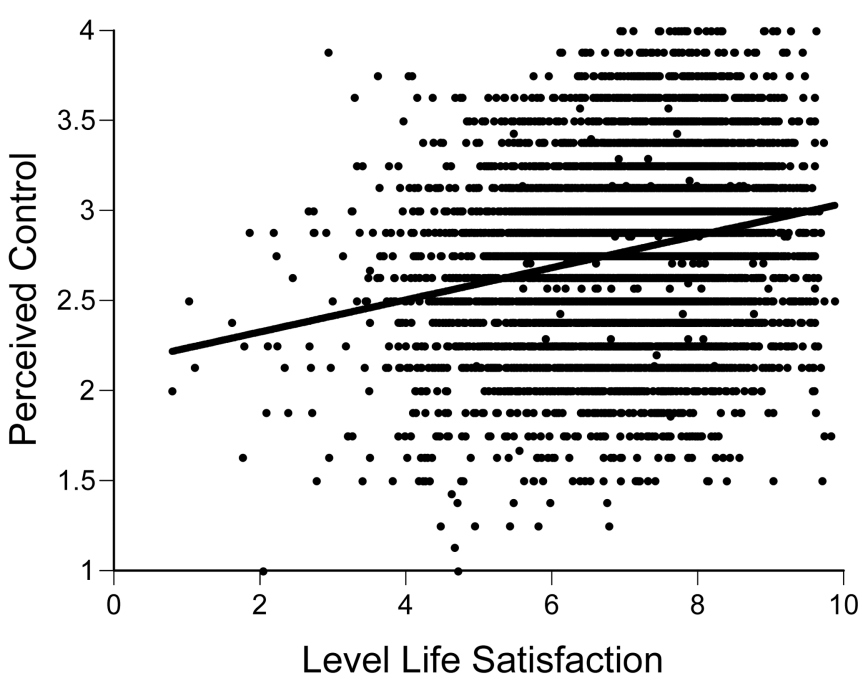

Figure 2.

Illustrating associations between levels of social participation and life satisfaction with perceived control in the SOEP study. Panels A and B show that participants reporting higher levels of social participation and life satisfaction, on average, were more likely to report higher levels of perceived control. The figure also highlights the tremendous amount of between-person heterogeneity in those associations. 
(A)

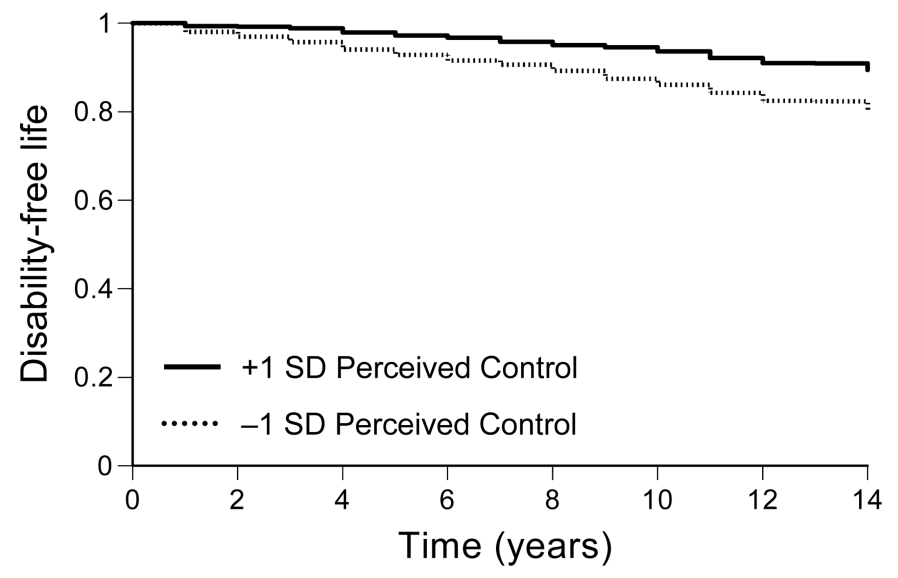

(B)

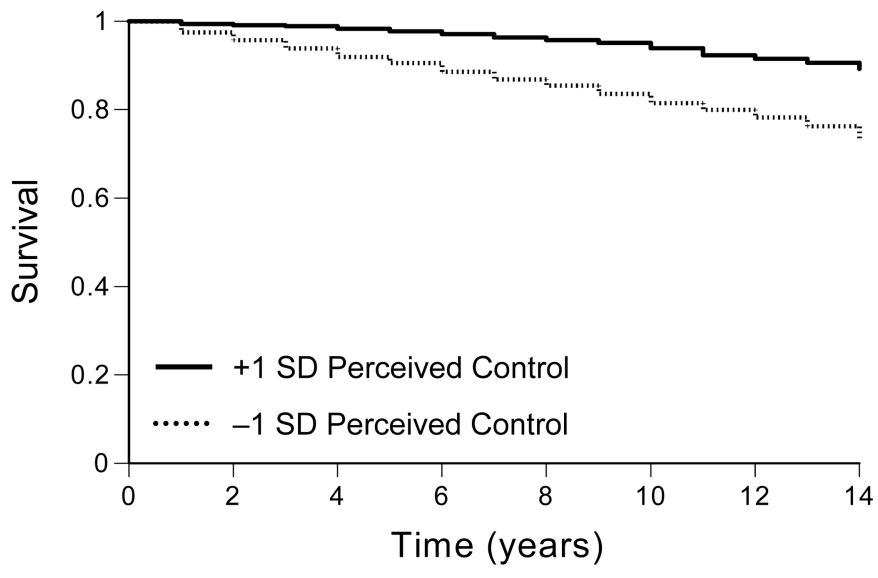

Figure 3.

Illustrating the predictive effects of perceived control for disability-free life (Panel A) and survival (Panel B) over 14 years in the 1994 sample of the national German Socioeconomic Panel (SOEP). SOEP participants with more perceived control were at lower risks for developing disability and mortality, respectively. For disability, the predictive effect of perceived control vanished after covarying for socio-demographic and psychosocial factors. For mortality, the predictive effect of perceived control was independent of sociodemographic and psychosocial factors. 


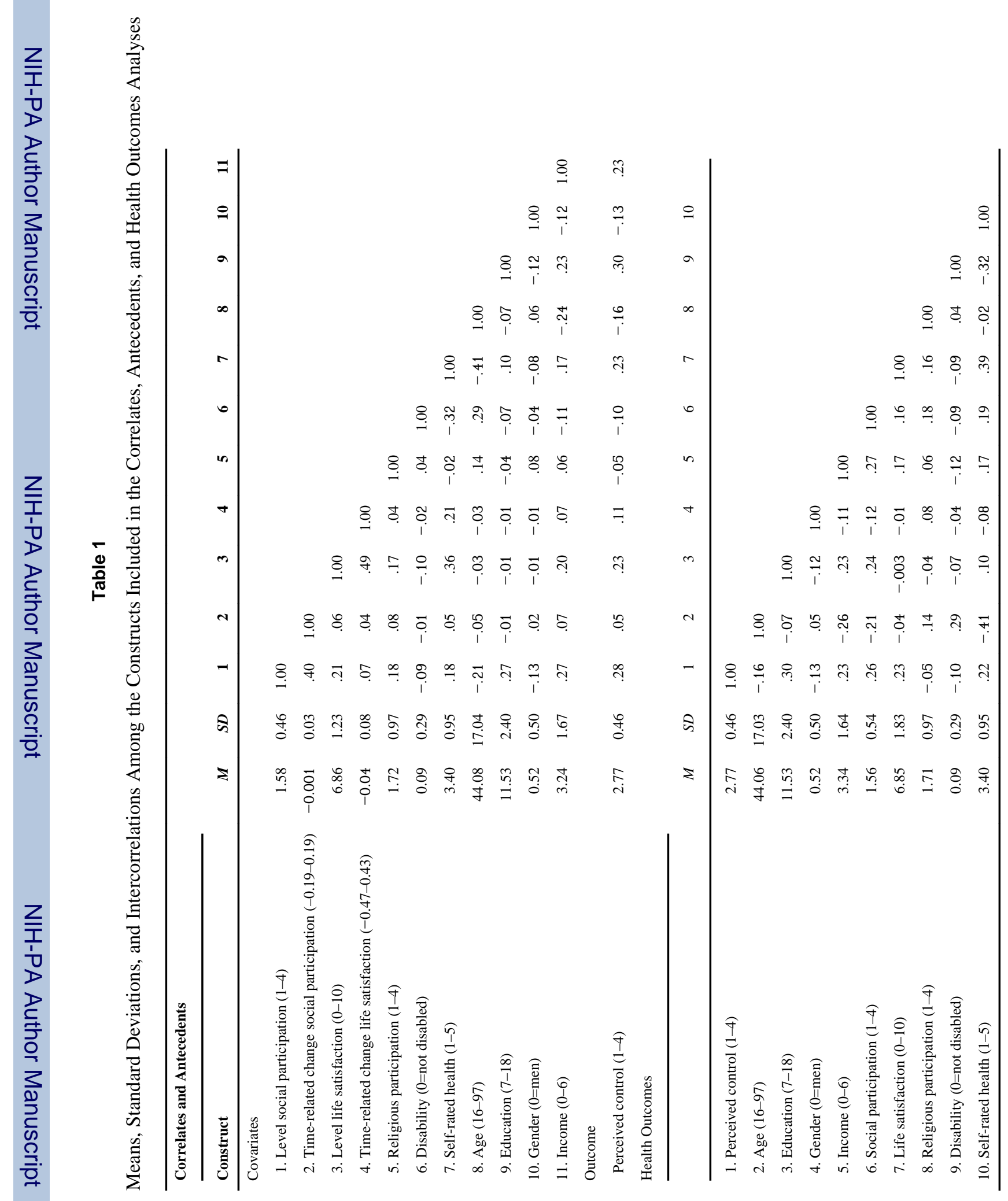




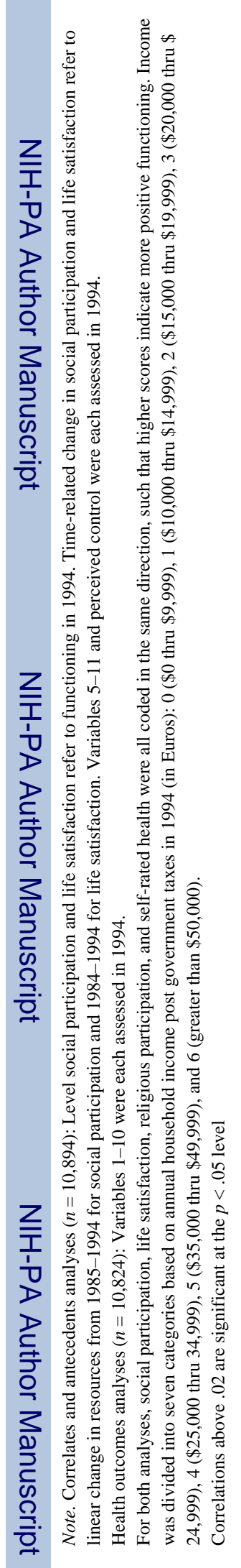




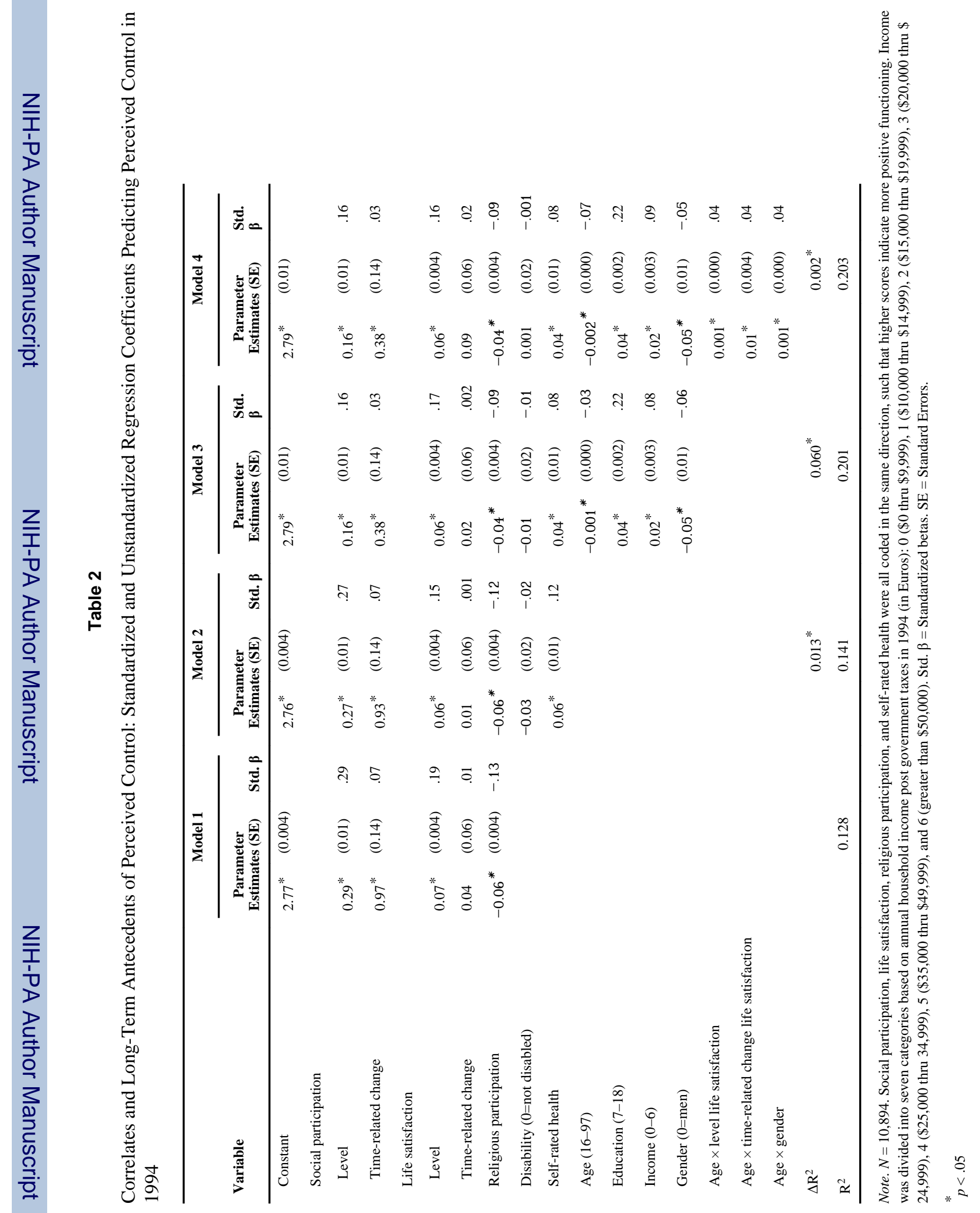




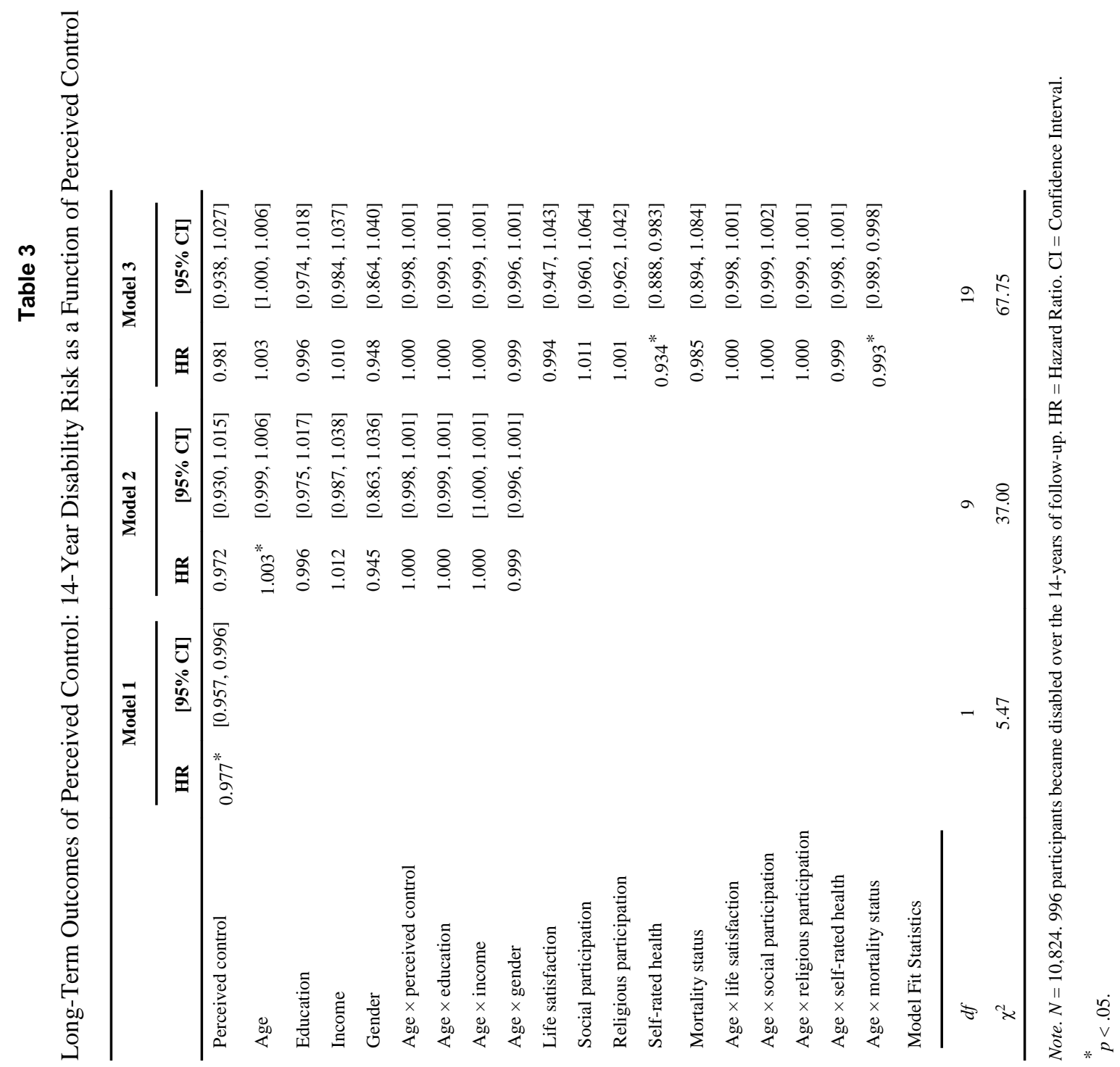

Psychol Aging. Author manuscript; available in PMC 2012 September 1. 


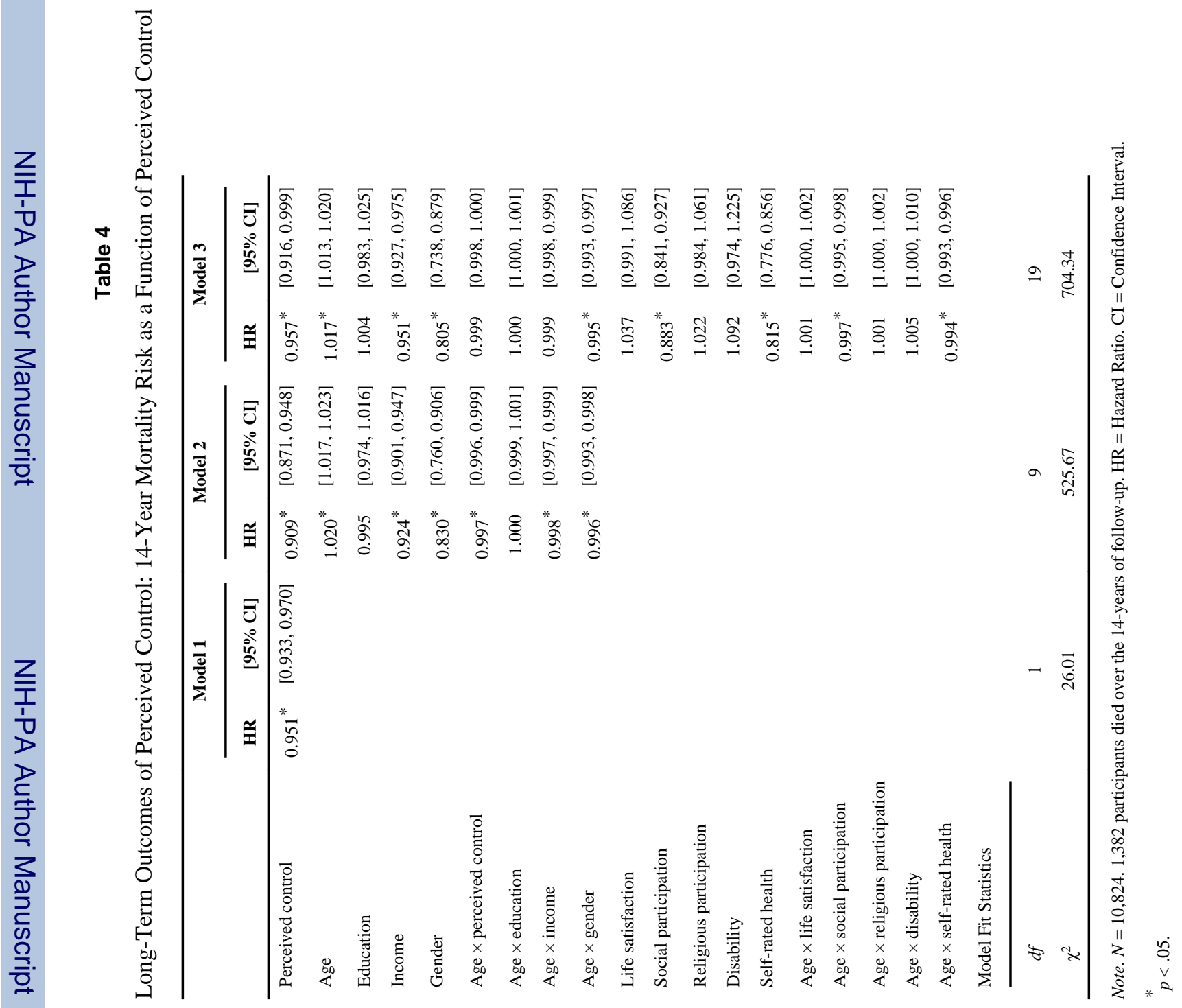

